\title{
O TRABALHO DE CATADORES E CATADORAS DE MATERIAIS RECICLÁVEIS NA COOPERMAR EM CUIABÁ-MT
}

\author{
Nielli Layane Dias Ribeiro ${ }^{1}$ \\ Silvia Fernanda Cantóia ${ }^{2}$
}

\section{Resumo}

O trabalho de catadores e catadoras de materiais recicláveis é essencial para que haja a implantação efetiva da Política Nacional de Resíduos Sólidos no Brasil. A organização destes trabalhadores em cooperativas assim como a organização de sistemas de gerenciamento e gestão de resíduos nos municípios é necessária e urgente. O artigo tem como objetivo elucidar o trabalho na cooperativa Coopermar na cidade de Cuiabá, apresentando partes do trabalho desenvolvido na coleta, separação e venda dos materiais recicláveis. Ressalta-se que o município não possui serviço de coleta seletiva efetivo, assim como há precarização do trabalho nesta cooperativa evidenciando a necessidade de investimentos e incentivos por parte do poder público municipal.

Palavras-chave: catador e catadora de materiais recicláveis, resíduo sólidos, cooperativas, trabalho.

\section{THE WORK OF WASTE PICKERS AND WASTE PICKERS OF RECYCLABLE MATERIALS AT COOPERMAR IN CUIABÁ-MT}

\begin{abstract}
The work of recyclable materials pickers is essential for the effective implementation of the National Solid Waste Policy in Brazil. The organization of these workers in cooperatives as well as the organization of waste management and management systems in the municipalities is necessary and urgent. The article aims to clarify the work in the Coopermar cooperative in the city of Cuiabá, presenting parts of the work developed in the collection, separation and sale of recyclable materials. It should be noted that the municipality does not have an effective selective collection service, as well as there is precarious work in this cooperative, highlighting the need for investments and incentives by the municipal government.
\end{abstract}

Keywords: recyclable material pickers, solid waste, cooperatives, work.

\footnotetext{
${ }^{1}$ Mestra em Geografia pelo programa de Pós-graduação em Geografia pela Universidade Federal de Mato Grosso. Email: niellilayane@hotmail.com.

${ }^{2}$ Professora Adjunta do Departamento de Geografia e docente permanente do Programa de Pós-graduação em Geografia da Universidade Federal de Mato Grosso. Email: silvinhacant@ gmail.com.
} 


\section{EL TRABAJO DE RECOLECTORES DE RESIDUOS Y RECOLECTORAS DE RESIDUOS DE MATERIALES RECICLABLES EN COOPERATIVAS CUIABÁ-MT}

\section{Resumen}

El trabajo de las recolectoras y los recolectores de materiales reciclables es fundamental para la implementación efectiva de la Política Nacional de Residuos Sólidos en Brasil. La organización de estos trabajadores en cooperativas, así como la organización de los sistemas de administración y gestión de residuos en los municipios es necesaria y urgente. El artículo tiene como objetivo esclarecer el trabajo en la cooperativa Coopermar en la ciudad de Cuiabá, presentando partes del trabajo desarrollado en la recolección, separación y venta de materiales reciclables. Se destaca que el municipio no cuenta con un servicio de recogida selectiva efectivo, así como el trabajo precario en esta cooperativa, evidenciando la necesidad de inversiones e incentivos por parte del gobierno municipal.

Palabras-clave: recolectoras y recolectores de materiales reciclables, residuos sólidos, cooperativas, trabajo.

\section{INTRODUÇÃO}

Pensar o trabalho de catadoras e catadores de materiais recicláveis no Brasil é dialogar com sujeitos que realizam ações diárias que são fundamentais para a organização dos resíduos gerados todos os dias e que são descartados pela população que na maioria das vezes não sabe o destino destes.

O consumo acelerado de uma variedade de produtos que contem uma diversidade de materiais inseridos em embalagens, coloridas, chamativas, geram uma desenfreada necessidade de se comprar, descartar, comprar. Neste ciclo na qual a lógica capitalista nos impulsa a ter, temos a dialética da negação para um grupo de sujeitos que não conseguem sequer comprar itens básicos para sua sobrevivência, eis as desigualdades vividas pela sociedade do consumo, que além de gerar resíduos, gera desemprego, fome, desilusão.

Debater a questão do trabalho requer pensar a organização social na qual estamos inseridos, além da perversidade da venda da força do trabalhador e trabalhadora, é pensar na renda em contrapartida com a mais valia, é a luta constante entre o capitalista e o assalariado.

Neste contexto, este trabalho tem como objetivo apresentar partes do trabalho realizado por catadores e catadoras de materiais recicláveis de uma cooperativa de resíduos sólidos no município de Cuiabá, a Coopermar. 
Além disso, revela a necessidade de políticas públicas efetivas que organizem o sistema de coleta seletiva da cidade, assim como o cumprimento da Política Nacional de Resíduos Sólidos (2010) que evidencia o papel significativo deste trabalhadores e trabalhadoras, que vivem na informalidade em diversos municípios do território brasileiro, que necessitam de organização social e política para saírem dos amontoados de lixo e resíduos presentes em lixões e assim se organizarem em cooperativas e associações que possuam elementos básicos para um trabalho digno.

A emancipação social que a PNRS (2010) traz em seu texto revela o salto qualitativo e necessário para que o país tenha um sistema de gerenciamento e gestão de resíduos que valorize a profissão do catador e catadora de materiais recicláveis, porém, é preciso que haja organização política para que se efetive tais medidas.

\section{A QUESTÃO DO TRABALHO E DO TRABALHADOR}

O trabalho cooperativo pode ser compreendido como ação conjunta de um grupo de pessoas que se organiza de modo coletivo, na busca de melhores condições de trabalho.

A formação das cooperativas possibilita novas relações entre os grupos de catadores de materiais recicláveis, criando diversas melhorias nas condições de vida e cidadania. Santos (2012, p.341) aponta para a valorização, profissionalização do trabalho do catador e catadora de materiais recicláveis, a inclusão social e o resgate da cidadania, bem como a retirada dos catadores e catadoras dos lixões e aterros.

O conceito de cooperativa nasce na economia socialista que tem entre os princípios a concepção um modo de produção sem a divisão de classe, nesse sentido, todos teriam os mesmos direitos, seriam donos por igual, conforme Singer (2003) não teria divisão entre a classe dominante, ou seja, os proprietários e a classe dos trabalhadores.

Quando são organizadas desse modo, as associações e as cooperativas de catadores de materiais recicláveis têm um papel fundamental que colabora na organização e na melhoria das condições de trabalho e de vida deste sujeitos, sendo uma alternativa para sair da situação de exploração vivenciadas por estes no lixão, à medida que, as cooperativas são organizadas com ex - catadores de materiais recicláveis e outros grupos de trabalhadores e trabalhadoras informais. 
O mundo do trabalho sob o novo complexo de reestruturação produtiva é permeado não apenas por novos tipos de controle do trabalho, mas principalmente por uma nova exclusão social, caracterizada pelo desemprego estrutural que atinge os polos industriais mais desenvolvidos (ALVES, 2000,p. 259).

Pensar o trabalho é descortinar os números e travar um debate sobre a evolução do desemprego e da informalidade, e no caso dos catadores e catadoras de materiais recicláveis é dialogar com sujeitos que ainda se encontram em situação de extrema vulnerabilidade catando dia a dia em lixões e aterros ou nas ruas das cidades. É pensar na pobreza, é pensar na fragilidade e negação do direto à vida,

A pobreza significa a incapacidade de participar no mercado de consumo. O desemprego sublinha a capacidade de participar do mercado da produção. Estes dois fenômenos, pobreza e desemprego, se bem que excluam diferencialmente do mercado, serão, pois, considerados como processos similares na sua maneira de rejeitar os homens para fora do que a sociedade moderna detém de mais invejável: a esfera dos bens e dos privilégios econômicos. Esta primeira forma de exclusão consiste, de facto, numa ruptura do laço econômico que liga fielmente, ou normativamente, os actores sociais ao modelo de sociedade (XIBERRAS, 1993, p.28).

Neste processo desigual, há a criação de subclasses na qual os sujeitos se enquadram em grupos para que juntos consigam lutar pela sobrevivência e com isso vão tecendo no dia a dia a criação de uma identidade

Se você foi destinado à subclasse (porque abandonou a escola, é mãe solteira vivendo da previdência social, viciado ou ex-viciado em drogas, sem-teto, mendigo ou membro de outras categorias arbitrariamente excluída da lista oficial dos que são considerados adequados e admissíveis), qualquer outra identidade que você possa ambicionar ou lutar para obter lhe é negada a priori. O significado da "identidade da subclasse" é a ausência de identidade, a abolição ou negação da individualidade, do "rosto" - esse objeto do dever ético e da preocupação moral. Você é excluído do espaço social em que as identidades são buscadas, escolhidas, construídas, avaliadas, confirmadas ou refutadas. A subclasse é um grupo heterogêneo de pessoas que - como diria Giorgio Agamben - tiveram o seu "bios", ou seja, a vida de um sujeito socialmente reconhecido reduzido a "zoe" (a vida puramente animal, com todas as ramificações reconhecidamente humanas podadas ou anuladas) (BAUMAN, 2007, p.46, grifo do autor).

Neste ir e vir, é necessário pensarmos em alternativas para essas trabalhadoras e trabalhadores neste contexto de opressão, acreditamos que a organização em grupos cooperativos seja um dos caminhos a serem seguidos possibilitando que esses sujeitos possam 
ser ouvidos, que tenham uma inserção social, que incite o repensar na forma como essa sociedade está estruturada.

O trabalho cooperativo permite que haja uma nova forma de se pensar o trabalho e a organização social, porém,

Nesse sentido, não podemos falar de um processo homogêneo e harmônico de construção identitária dos sujeitos trabalhadores em configurações socioprodutivas autogestionárias e solidárias. Existe uma pluralidade e diversidade de identificações com o projeto cooperativista e autogestionário, tendo esses sujeitos que enfrentar e tratar muitos conflitos e problemas, relativos às diferentes dimensões inerentes ao processo em construção, ou seja, econômico-jurídico, político-administrativo e psicossocial. É necessário e urgente repensar-se a gestão desses empreendimentos, buscando-se formas mais democráticas e transparentes de organização, que possibilitem a expressão das diferenças, das singularidades dos sujeitos. É nesse sentido que a identidade e autonomia se configuram como processos em construção. A identidade de ser alguém autônomo em nossa sociedade heterônoma não é simples, mas os empreendimentos autogestionários têm demonstrado a possibilidade real nesta via. Para além de uma saída à crise do capital, os movimentos de autogestão e socioeconomia solidária têm se constituído como uma viabilidade para uma nova sociabilidade humana, ou seja, que não pode ser outra, a da criação de sujeitos humanos autônomos e livres. (TRAJANO E CARVALHO, 2003, p.175).

Dessa maneira, a Economia Solidária surge como resposta à crise do sistema capitalista de produção. Segundo Zanin e Gutierrez (2011, p.39),

[...] Surgem os empreendimentos econômicos solidários (EES) de catadores de resíduos sólidos que estão sendo criados em diversos municípios como alternativa para a humanização e formalização do trabalho dos catadores junto aos sistemas de coleta de resíduos, nos quais exercem atividades de coleta, triagem de resíduos sólidos e comercialização. De acordo com o Atlas da Economia Solidária no Brasil (BRASIL, Secretaria Nacional de Economia Solidária, 2007), foram identificados 21.859 empreendimentos econômicos solidários 15, sendo que aproximadamente 500 empreendimentos (mais de 13 coleta e triagem de resíduos. No estado de São Paulo foram identificados 115 empreendimentos de coleta e triagem de resíduos com mais de 3000 catadores organizados. Todos os empreendimentos de economia solidária guardam grande semelhança entre si uma vez que são caracterizados por algum tipo de atividade econômica, pela cooperação, pela solidariedade e pela autogestão. Estas práticas sociais e econômicas além de privilegiarem a propriedade coletiva também beneficiam a justiça social, o cuidado com o meio ambiente e o cuidado com as gerações futuras (ZANIN E GUTIERREZ, 2011 apud BRASIL, 2006, grifos dos autores).

Porém, ressalta-se que muitas cooperativas e associações de catadoras e catadores de materiais recicláveis não possuem sequer infraestrutura adequada para realizarem o trabalho, 
assim como falta de políticas municipais efetivas para manutenção das cooperativas ou associações. Além disso, não há um sistema de coleta seletiva implantado o que impacta diretamente a vida dos catadores, assim como ações educativas para que haja conhecimento da população sobre estes trabalhadores e trabalhadoras o que aumenta a lacuna entre a autogestão, autonomia e emancipação destes sujeitos.

Devemos elucidar que tais ações são de responsabilidade do poder público, e que a questão dos resíduos é um problema de saúde pública e por isso deve ser planejada de maneira adequada.

Pensar a gestão e gerenciamento dos resíduos sólidos como aponta a PNRS (2010), com inserção dos catadores de materiais recicláveis é algo extremamente necessário, assim como o fechamento de lixões a céu aberto, a criação de cooperativas e associações, campanhas educativas que informem a população sobre formas de descarte. Essas ações planejadas geram sistemas efetivos de coleta seletiva, possibilitando menor impacto ao meio pois possibilitam que inúmeras toneladas de lixo cheguem aos locais de disposição.

Segundo os dados do Panorama dos resíduos sólidos 2018/2019, publicado pela Associação Brasileira de Empresas de Limpeza Pública e Resíduos Especiais (Abrelpe),

Os dados revelam que, em 2018, foram geradas no Brasil 79 milhões de toneladas, um aumento de pouco menos de $1 \%$ em relação ao ano anterior. Desse montante, $92 \%$ (72,7 milhões) foi coletado. Por um lado, isso significa uma alta de 1,66\% em comparação a 2017: ou seja, a coleta aumentou num ritmo um pouco maior que a geração. Por outro, evidencia que 6,3 milhões de toneladas de resíduos não foram recolhidas junto aos locais de geração. A destinação adequada em aterros sanitários recebeu 59,5\% dos resíduos sólidos urbanos coletados: 43,3 milhões de toneladas, um pequeno avanço em relação ao cenário do ano anterior. $\mathrm{O}$ restante $(40,5 \%)$ foi despejado em locais inadequados por 3.001 municípios. Ou seja, 29,5 milhões de toneladas de RSU acabaram indo para lixões ou aterros controlados, que não contam com um conjunto de sistemas e medidas necessários para proteger a saúde das pessoas e o meio ambiente contra danos e degradações. (ABRELPE ,2018/2019)

Diante dos dados percebe-se que é necessário um repensar estratégico dos gestores púbicos para que haja efetivação de ações referentes aos resíduos sólidos, assim como repensar nossa prática e consumo.

Segundo dados da CEMPRE (2016) ,82\% dos municípios brasileiros não possuem serviço de coleta seletiva e, 
A coleta seletiva dos resíduos sólidos municipais é feita pela própria Prefeitura em $51 \%$ das cidades pesquisadas; Empresas particulares são contratadas para executar a coleta em $67 \%$; E praticamente metade (44\%) apoia ou mantém cooperativas de catadores como agentes executores da coleta seletiva municipal. $\mathrm{O}$ apoio às cooperativas está baseado em: maquinários, galpões de triagem, ajudas de custos com água e energia elétrica, caminhões (incluindo combustível), capacitações e investimento em divulgação e educação ambiental. (CEMPRE, 2016)

Percebe-se que não há informações sobre a contratação de cooperativas de catadores e catadoras de materiais recicláveis pelos serviços de coleta seletiva o que aumenta os desafios destes trabalhadores que ainda não recebem a valorização necessária.

\section{O TRABALHO COOPERATIVO}

Tendo em vista a questão dos resíduos sólidos e a organização de catadores e catadoras de materiais recicláveis como forma de organização, temos na cidade de Cuiabá-MT, três cooperativas e uma associação de catadoras e catadores de materiais recicláveis, sendo: COOREPAM (Cooperativa Alternativa de Catadores e Reciclagem e Preservação do Meio Ambiente do Estado de Mato Grosso); COOPERMAR (Cooperativa dos Trabalhadores da Reciclagem do Estado de Mato Grosso), COOPUNIÃO (Cooperativa de Trabalho União de Catadores de Materiais Recicláveis de Cuiabá) e ACAMARC (Associação de Catadores de Materiais Recicláveis).

Delimitamos nesta pesquisa a cooperativa Coopermar que se divide em duas unidades, em endereços diferentes, a Coopermar -Unidade de Beneficiamento, Coopermar Jardim Umuarama que realiza a coleta, triagem e venda de materiais recicláveis.

Na cidade de Cuiabá não há a implantação de sistema de coleta seletiva efetivo, o que gera muitos problemas para as cooperativas e associação que fazem o trabalho de coleta, e por isso optam em coletar os resíduos de grandes geradores se dividindo por regiões da cidade, porém, como não há o descarte seletivo, ou seja, todo o resíduo descartado, seja reciclável ou não vai para as cooperativas e associações o trabalho na separação é insalubre e perverso.

Nos trabalhos de campo realizados entre os anos 2018 e 2019, percebemos que as cooperativas possuem infraestrutura degradante, não oferecendo condições básicas de trabalho, não há banheiros adequados, espaço para alimentação, além de não possuírem estrutura para se protegerem. Ademais, não possuem todos os equipamentos necessários para um trabalho digno.

Quando não há um sistema de coleta seletiva que segue os passos necessários, ou seja, o descarte correto realizado pela população, a coleta seletiva com caminhões adequados, e 
infraestrutura básica para a separação, enfardamento e venda dos materiais recicláveis observamos que os catadores e catadores ficam expostos a situações degradantes na realização do trabalho.

Há que se repensar a lógica de como entendemos os resíduos sólidos gerados, assim como conhecermos o trabalho dos catadores e catadoras de materiais recicláveis espalhados pelo território nacional.

\section{Breve diagnóstico das catadoras e catadores de materiais recicláveis da Coopermar.}

A fim de que pudéssemos conhecer um pouco mais sobre estes sujeitos, aplicamos questionários junto aos catadores e catadoras da Coopermar. A base para elaboração das perguntas teve com base em Cantóia (2012), e tiveram os seguintes temas: identificação, escolaridade, renda, comercialização, equipamentos e veículos utilizados, saúde do trabalhador.

Para análise destes dados foram organizados quadros divididos em identificação dos catadores e catadoras. e estrutura e funcionamento da cooperativa. No quadro 1, temos a organização dos dados fornecidos pelos catadores e catadoras que se propuseram responder o questionário.

Quadro 1. Identificação dos cooperados da unidade de beneficiamento cooperativa Coopermar

\begin{tabular}{|c|c|c|c|c|}
\hline \multirow[b]{2}{*}{ Questionário } & \multicolumn{4}{|c|}{ Identificação 1 - Cooperativa Coopermar unidade de beneficiamento } \\
\hline & 1 & 2 & 3 & 4 \\
\hline Qual a idade? & 47 anos & 48 anos & 46 anos & 56 anos \\
\hline $\begin{array}{l}\text { Em relação a cor da pele, você se } \\
\text { considera? }\end{array}$ & Branca & Preta & Preta & Preta \\
\hline Qual a situação conjugal? & Casado & Casado & Casado & Solteiro \\
\hline Qual a sua escolaridade? & Não estudou & $3^{\circ}$ ano & Não estudou & Não estudou \\
\hline Qual a origem de trabalho? & $\begin{array}{l}\text { Fábrica de } \\
\text { panela }\end{array}$ & Fazenda & $\begin{array}{l}\text { Construção } \\
\text { Civil }\end{array}$ & Outro \\
\hline Qual o cargo na cooperativa? & $\begin{array}{l}\text { Processo final } \\
\text { moinho }\end{array}$ & $\begin{array}{l}\text { Processo final } \\
\text { moinho }\end{array}$ & - & - \\
\hline Quantas horas trabalha por dia? & $6: 30$ horas & $6: 30$ horas & $6: 30$ horas & $6: 30$ horas \\
\hline $\begin{array}{l}\text { Há quanto tempo trabalha na } \\
\text { cooperativa }\end{array}$ & 16 anos & $\begin{array}{l}25 \text { anos, desde } \\
1997\end{array}$ & 5 anos & 22 anos \\
\hline $\begin{array}{l}\text { O trabalho cooperado é a única } \\
\text { fonte de renda? }\end{array}$ & Sim & Sim & Sim & Sim \\
\hline $\begin{array}{l}\text { Quantas pessoas na moram na } \\
\text { casa? }\end{array}$ & 2 pessoas & 4 pessoas & 4 pessoas & 5 pessoas \\
\hline Tem filhos, quantos? & 3 filhos & 2 filhos & $\begin{array}{l}\text { Tenho, mas sou } \\
\text { separado }\end{array}$ & 3 filhos e 1 neta \\
\hline
\end{tabular}

Organização: Ribeiro, 2019 
Com base nas informações presentes no quadro 1 de identificação, percebe-se que dos cooperados que responderem o questionário, todos apresentam paridade de faixa etária entre 46 e 56 anos, e são trabalhadores que estão na cooperativa há muitos anos, sendo que um deles está trabalhando desde 1997. Todos afirmam que a única fonte de renda de família vem da cooperativa, e que a carga horária de trabalho é de 6:30 horas diárias. A maioria não frequentou a escola, apresentando um constrangimento por não conseguirem ler nem escrever ${ }^{3}$.

Ao olhar para os catadores e catadoras de materiais recicláveis, e suas respostas percebese que se sentiram fragilizados e/ou inibidos por terem pouco ou nenhuma escolaridade, que encontraram no trabalho cooperado com recicláveis a possibilidade de prover o sustendo de suas famílias, uma vez que, a única fonte de renda vem da cooperativa.

O Quadro 2 apresenta os dados referendes a instalação e funcionamento da unidade de beneficiamento da cooperativa Coopermar.

Quadro 2. Dados referendes a instalação e funcionamento da unidade de beneficiamento da cooperativa Coopermar

\begin{tabular}{|c|c|c|c|c|c|c|}
\hline \multicolumn{7}{|c|}{2 - Instalações - Cooperativa Coopermar unidade de beneficiamento } \\
\hline \multicolumn{2}{|l|}{ Endereço: } & \multicolumn{5}{|c|}{ Estrada Balneário Leticia, S/N, KM 06 Várzea do Quilombo. } \\
\hline \multicolumn{2}{|l|}{ Prédio: } & \multicolumn{5}{|c|}{ Cedido pela prefeitura } \\
\hline \multicolumn{2}{|l|}{ Infraestrutura: } & \multicolumn{5}{|c|}{ Unidade de beneficiamento } \\
\hline \multicolumn{7}{|l|}{3 - Dados gerais } \\
\hline \multicolumn{2}{|c|}{ Quem realiza a coleta seletiva? } & \multicolumn{5}{|c|}{$\begin{array}{l}\text { Cooperativa de catadores de materiais recicláveis - Unidade Jardim } \\
\text { Umuarama }\end{array}$} \\
\hline \multicolumn{2}{|c|}{ Qual a área de abrangência? } & \multicolumn{5}{|c|}{-} \\
\hline \multicolumn{2}{|c|}{ Qual a frequência da coleta seletiva? } & - & \multicolumn{3}{|c|}{ Utiliza-se balança para pesagem? } & Sim \\
\hline \multicolumn{2}{|c|}{ Que tipo de material é recolhido? } & \multicolumn{2}{|c|}{ Tonelada/mês } & \multicolumn{3}{|c|}{ Porcentagem $(\%)$ no total } \\
\hline \multicolumn{2}{|l|}{ PET } & \multirow{3}{*}{\multicolumn{2}{|c|}{ Não souberam responder }} & \multirow{3}{*}{\multicolumn{3}{|c|}{ Não souberam responder }} \\
\hline \multicolumn{2}{|l|}{ PEAD } & & & & & \\
\hline \multicolumn{2}{|l|}{ Seda } & & & & & \\
\hline \multicolumn{7}{|c|}{$\begin{array}{l}\text { A Unidade trabalha com o beneficiamento do Plástico que vem da outra unidade, também realizam a compra } \\
\text { do plástico da Coopunião. }\end{array}$} \\
\hline \multicolumn{7}{|c|}{4 - Comercialização } \\
\hline \multicolumn{3}{|c|}{\begin{tabular}{|l|l} 
Material & Quem são os compradores?
\end{tabular}} & \multicolumn{2}{|c|}{ Com que frequência? } & \multicolumn{2}{|c|}{ Quanto é vendido? } \\
\hline $\begin{array}{ll}\text { Plásticos já } \\
\text { beneficiado }\end{array}$ & Indústria & & Não soub & $\mathrm{m}$ responder & $\begin{array}{l}\text { Não } \\
\text { respond }\end{array}$ & ouberam \\
\hline \multicolumn{7}{|c|}{5 - Equipamentos e Veículos Utilizados } \\
\hline Equipamento & \multicolumn{2}{|l|}{ Quantidade } & \multicolumn{2}{|l|}{ Próprio } & \multicolumn{2}{|l|}{ Cedido } \\
\hline Moinho & \multicolumn{2}{|l|}{1} & \multicolumn{2}{|l|}{$\mathrm{X}$} & & \\
\hline Secadores & 1 & & $\mathrm{X}$ & & & \\
\hline Aglutinadora & & & $X$ & & & \\
\hline
\end{tabular}

${ }^{3}$ Devido as dificuldades apresentadas pelos cooperados de leitura e escrita, foi realizado pelas pesquisadoras a leitura e o preenchimento dos questionários. 


\begin{tabular}{|l|l|l|}
\hline máquina extrusora & 1 & X \\
\hline 6- Saúde do trabalhador & $\begin{array}{l}\text { Sim - mas não para } \\
\text { todos }\end{array}$ \\
\hline A cooperativa oferece equipamentos de proteção individual (EPI's) & $\begin{array}{l}\text { Botas e Protetor } \\
\text { Auricular }\end{array}$ \\
\hline Quais os EPI'S são utilizados? & Nenhum \\
\hline Quantos acidentes de trabalho foram registrados? & \\
\hline
\end{tabular}

Organização: Ribeiro, 2019

A unidade de beneficiamento da Coopermar, trabalha com resíduos de plástico. $\mathrm{O}$ plástico utilizado chega à cooperativa de duas maneiras, a primeira vem da unidade Coopermar Jardim Umuarama que coleta e separa os materiais e depois realizam a transporte até a unidade, o segundo é feito pela compra do plástico, que é realizada com outra cooperativa. Esse processo de compra mostra uma relação que se estabelece de comércio entre as duas cooperativas e impulsiona a renda entre os catadores e catadoras de materiais recicláveis. ${ }^{4}$

O beneficiamento do plástico é uma parte importante dentro do sistema de valorização da cooperativa, através desse processo é possível comercializar diretamente para a indústria, o que pode contribuir para aumentar a renda das cooperadas e dos cooperados.

Em relação a comercialização, quando perguntamos aos cooperados fomos informadas que a cooperativa comercializa os fardos dos granulados diretamente com a indústria, e que esse material é utilizado para a construção de tubos e mangueiras.

Em relação aos EPI'S - Equipamentos de Proteção Individual, as respostas nos questionários apontam que não há para todos, mas que possuem alguns dos itens como: botas e protetores auriculares. É importante realçarmos que as atividades que têm riscos físico, devem utilizar os EPI's, o uso é essencial para garantir a segurança evitando acidentes de trabalho.

Considera-se que a infraestrutura de uma cooperativa é fundamental para o desenvolvimento do trabalho, como sede própria, galpão espaçoso, banheiros, e equipamentos adequados, e outros. Em relação e esse quesito com base nas informações disponíveis no quadro e trabalhos de campo observamos na figura 01 , que as instalações não oferecem infraestrutura mínima, para estes trabalhadores.

\footnotetext{
${ }^{4}$ A cooperativa que vende os plásticos é a Coopunião e divide o mesmo espaço do galpão com a Coopermar, por isso não há atravessadores e a compra é direta.
} 


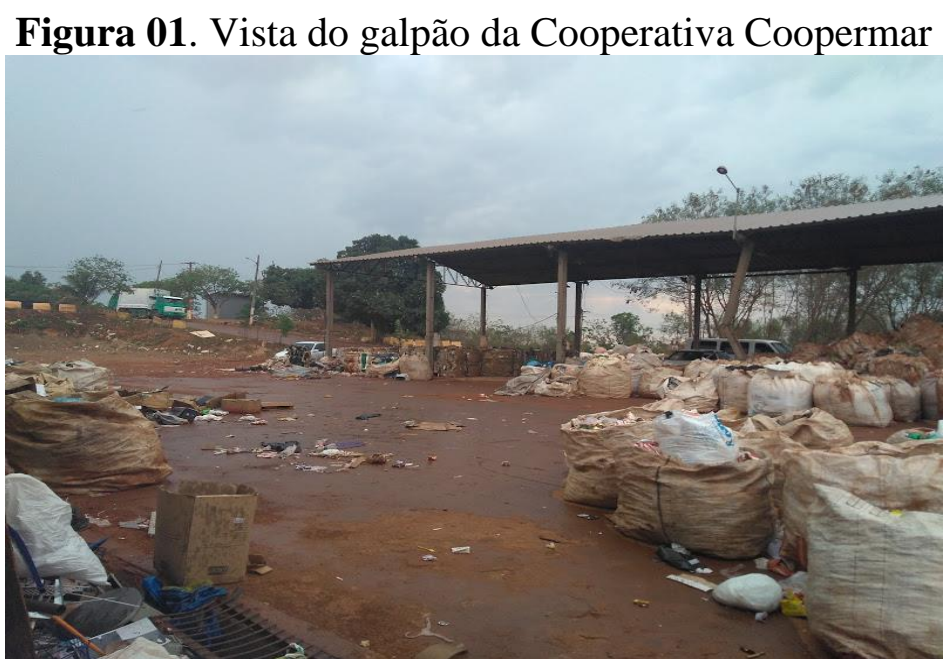

Fonte. Cantoia, 2019

Considera-se que o trabalho cooperado possibilita às famílias um meio de desenvolver seu trabalho em melhores condições, quando comparados aos catadores que estão no lixão, mas, ainda assim, não os isenta de trabalhar em condições de precariedade, conforme relevam a foto 01. Nota-se que os catadores ficam expostos às intempéries climáticas, além de não possuírem local adequado para armazenamento dos resíduos que ficam expostos.

Nos trabalhos de campo evidenciamos que os únicos equipamentos que possuem e estão funcionando são os destinados para o beneficiamento dos plásticos, porém, para a separação dos materiais recicláveis que chegam da coleta sequer possuem esteira, realizando o trabalho de separação no chão ou em mesas construídas por eles

Sendo assim, os resíduos plásticos são separados de acordo com suas características, plástico duro, que são as embalagens de produtos de limpeza, as caixas de hortifrúti ( $\mathrm{PP}$ Polipropileno e PEAD- Polietileno de Alta Densidade) garrafas de refrigerante, garrafas de água mineral (PET- Poli Tereftalato de Etileno, PEAD e PP) o plástico fino; as sacolas e geral (PEBD - Polietileno de Baixa Densidade).

Para realizar o beneficiamento contam com os seguintes maquinários, moinho, secadora e a extrusora. Os resíduos plásticos passam por quatro etapas, a primeira consiste na separação (figura 02), os materiais são levados para a moagem, que que reduz o seu tamanho. Na segunda etapa ocorre a lavagem e a separação, os fragmentos são lavados com água, e a separação é realizada de acordo com a densidade, os com maior densidade afundam e os menos densos ficam na superfície.

Posteriormente os fragmentos passam pelos secadores que utilizam a circulação de ar quente para que fiquem secos de modo homogêneo. A última etapa é a extrusão, os fragmentos 
secos são inseridos na máquina extrusora, onde são fundidos, em seguida esse material passa por orifícios que dão forma de filamentos (espaguetes), que são resfriados em uma banheira contendo água em temperatura ambiente e são cortados em granulados (figura 03).

Figuras 02 e 03. Processo de transformaçaõ do beneficiamento do plástico.
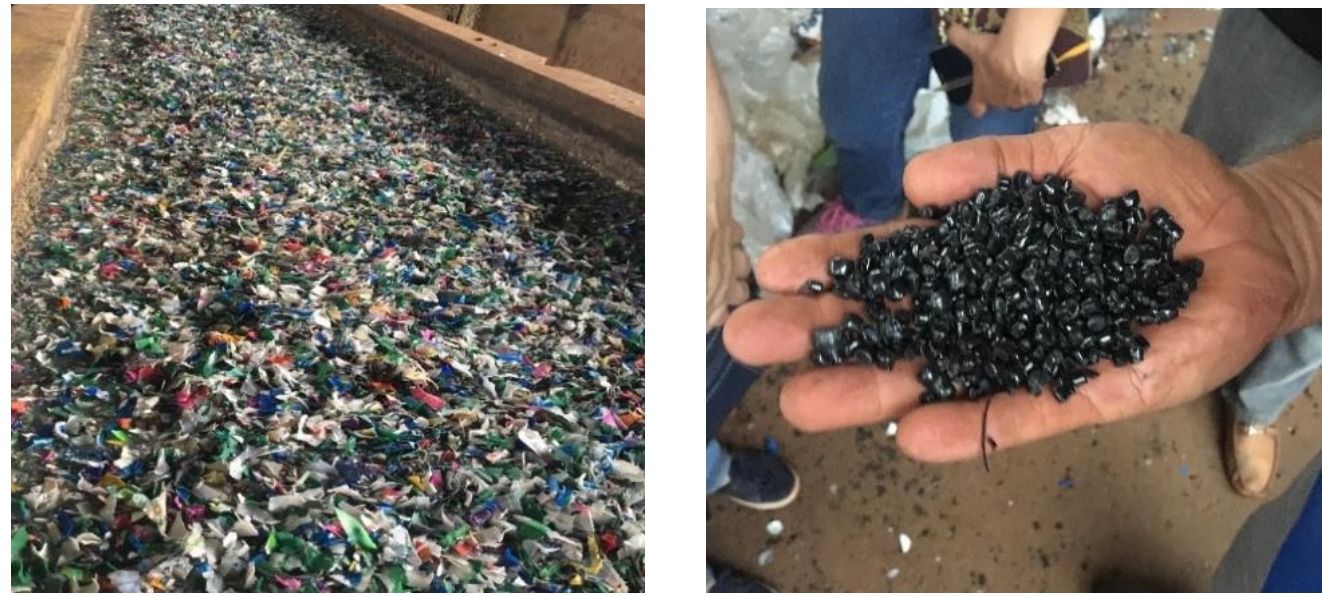

Fonte: Ribeiro, 2018.

Todo este processo de separação dos materiais recicláveis e beneficimanto do plástico realizado pelos cooperados e cooperadas exemplifica a necessidade de cumprimento da PNRS (2010), pois, se encontram em situação precária no e do trabalho. Além de não possuirem infraestrutura básica não são contratados pela Prefeitura Municipal o que agrava ainda mais a situação, pois, ficam a mercê das oscilações do mercado de resíduos.

A situação vivenciada pelos cooperados e cooperadas da Coopermar, unidade Jardim Umuarama são evidenciadas nos quadros $3 \mathrm{e} 4$ e foram desenvolvidos com base nos questionários respondidos. Nesta unidade é realizado o trabalho de coleta, separação e armazenamento dos materiais recicláveis sem nenhum tipo de transformação de produtos.

Quadro 3. Dados referendes a identificação dos cooperados da Coopermar localizada na unidade do Jardim Umuarama

\begin{tabular}{|c|c|c|c|c|c|c|}
\hline \multirow[b]{2}{*}{ Questionário } & \multicolumn{6}{|c|}{ Identificação 1 - Cooperativa Coopermar Jardim Umuarama } \\
\hline & 1 & 2 & 3 & 3 & 5 & 6 \\
\hline Qual a idade? & 45 anos & 35 anos & 28 anos & 51 anos & 43 anos & 32 anos \\
\hline $\begin{array}{l}\text { Em relação a cor } \\
\text { da pele, você se } \\
\text { considera? }\end{array}$ & $\begin{array}{l}\text { Prefiro não } \\
\text { declarar }\end{array}$ & Parda & Parda & Parda & $\begin{array}{l}\text { Prefiro não } \\
\text { declarar }\end{array}$ & Pardo \\
\hline $\begin{array}{l}\text { Qual a situação } \\
\text { conjugal? }\end{array}$ & Solteira & Casada & Solteira & Solteira & Casado & Casado \\
\hline $\begin{array}{l}\text { Qual a sua } \\
\text { escolaridade? }\end{array}$ & Não estudou & $8^{\circ}$ ano & $5^{\circ}$ ano & $8^{\circ}$ ano & $3^{\circ}$ ano & $1^{\circ}$ ano \\
\hline $\begin{array}{l}\text { Qual a origem de } \\
\text { trabalho? }\end{array}$ & Doméstica & Lixão & Outros & Faxina & Lixão & Lixão \\
\hline $\begin{array}{l}\text { Qual o cargo na } \\
\text { cooperativa? }\end{array}$ & Separação & - & No papelão & - & Prensador & Prensador \\
\hline
\end{tabular}




\begin{tabular}{|l|l|l|l|l|l|l|}
\hline $\begin{array}{l}\text { Quantas horas } \\
\text { trabalha por dia? }\end{array}$ & 6 a 8 horas & $\begin{array}{l}\text { Das 07h as } \\
17 \mathrm{hs}\end{array}$ & $\begin{array}{l}\text { Das 07h as } \\
17 \mathrm{hs}\end{array}$ & $\begin{array}{l}\text { Das 07h } \\
\text { as 17hs }\end{array}$ & 6 a horas & 10 horas \\
\hline $\begin{array}{l}\text { Há quanto tempo } \\
\text { trabalha na } \\
\text { cooperativa? }\end{array}$ & 8 anos & 5 anos & 3 anos & 23 anos & 2 meses & 3 anos \\
\hline $\begin{array}{l}\text { O trabalho } \\
\text { cooperado é a } \\
\text { única fonte de } \\
\text { renda? Sim }\end{array}$ & Sim & $\begin{array}{l}\text { Sim - mas } \\
\text { recebo bolsa } \\
\text { família }\end{array}$ & Sim & Sim & Sim \\
\hline $\begin{array}{l}\text { Quantas pessoas } \\
\text { na moram na } \\
\text { casa? Sozinha }\end{array}$ & 5 pessoas & 4 pessoas & - & 6 pessoas & 5 pessoas \\
\hline $\begin{array}{l}\text { Tem filhos, } \\
\text { quantos? }\end{array}$ & 2 filhos & 3 filhos & 3 filhos & 3 filhos & 4 filhos & 3 filhos \\
\hline Total de 4 cooperadas e 2 cooperados responderam ao questionário & \\
\hline
\end{tabular}

Organização: Ribeiro, 2019

Segundo as informações disponibilizadas pelo presidente da cooperativa Coopermar durante trabalhos de campo, esta unidade conta com um total de 18 catadores de materiais recicláveis, dentro desde grupo percebe-se um maior número de mulheres sendo 11 no total, sobre esse assunto o autor Lajolo (2003) comenta que:

[...] as mulheres possuem maior senso comunitário e a grande presença de mulheres facilita o trabalho social, elas ouvem mais, acreditam mais na possibilidade de transformar suas vidas e bebem menos que os homens. (LAJOLO, 2003, p. 25).

Além das possibilidades supracitadas, considera-se que a mulher tem papel significativo na sociedade e na cooperativa.

Nota-se nas respostas que estas mulheres desenvolvem vários papéis, o de profissional, de responsáveis pela casa, companheira, mães, algumas solteiras. Estas mulheres acumulam suas funções para possibilitar a renda e a sobrevivência de suas famílias. Em relação a escolaridade, notou-se que somente uma das cooperadas não frequentou a escola ${ }^{5}$, os demais possuem pouca escolaridade.

Durante a aplicação do questionário a maioria apresentava certa dificuldade de entender as questões. Ainda assim, percebeu-se que os cooperados ficaram mais tranquilos para responderem o questionário, sentaram-se juntos nas mesas e auxiliavam uns aos outros na leitura e escrita.

\footnotetext{
${ }^{5}$ Devido à dificuldade apresentada por uma das cooperadas de leitura e escrita, foi realizado pela pesquisadora a leitura e o preenchimento dos questionários.
} 
A faixa etária é bem variada, entre 28 a 51 anos, e o tempo em que estão trabalho como cooperados varia entre 2 meses a 23 anos. Em relação ao trabalho que desenvolviam antes de trabalharem como cooperados, três responderam que eram catadores no lixão.

Em um dos espaços do questionário havia um campo na qual poderiam, se quisessem, relatar sobre a profissão que exerciam antes da catação de materiais recicláveis e dois catadores responderam que,

Gosto de trabalhar aqui, melhor que na faxina, aqui eu ganho mais. (Catadora cooperada, 51 anos).

Cinco anos trabalhando no lixão, aqui é bem melhor, quando estava lá no lixão fiquei doente, fiquei internado mais de uma semana na UPA do Verdão, tive hemorragia. Quando voltei a trabalhar no lixão o cheiro era muito forte e passei mal. Agora tem dois meses que estou trabalhando aqui. (Catador cooperado, 43 anos).

A partir dos dois relatos, percebe-se que os cooperados comentam sobre a melhora da qualidade e das condições em que desenvolvem suas funções, além das questões de melhoria de salário. O catador que está trabalhando há 2 meses na cooperativa, por exemplo, expressa em sua fala as dificuldades enfrentadas no trabalho no lixão, que fez com que o mesmo ficasse enfermo, quando apresentou melhora e voltou a trabalhar no lixão, não conseguiu, devido os odores, o que ocasionou em uma piora de sua saúde.

Sobre a infraestrutura e funcionamento da cooperativa, agrupamos no quadro 4 , as respostas dos cooperados e cooperadas.

Quadro 4. Dados referendes a instalação e atuação da Coopermar localizada na unidade do Jardim Umuarama

\begin{tabular}{|c|c|c|c|}
\hline \multicolumn{4}{|c|}{2 - Instalações - Cooperativa Coopermar Jardim Umuarama } \\
\hline Endereço: & \multicolumn{3}{|l|}{ Av. Principal Jardim Umuarama s/n } \\
\hline Prédio: & \multicolumn{3}{|l|}{ Cedido pela prefeitura } \\
\hline \multirow{5}{*}{ Infraestrutura: } & \multicolumn{3}{|l|}{ Área de triagem } \\
\hline & \multicolumn{3}{|l|}{ Área de armazenamento } \\
\hline & \multicolumn{3}{|l|}{ Cozinha/Refeitório } \\
\hline & \multicolumn{3}{|l|}{ Escritório - não está funcionando } \\
\hline & \multicolumn{3}{|l|}{2 banheiros } \\
\hline \multicolumn{4}{|l|}{3 - Dados gerais } \\
\hline Quem realiza a coleta seletiva? & \multicolumn{3}{|c|}{$\begin{array}{l}\text { A cooperativa - a prefeitura retirou os caminhos, agora a cooperativa } \\
\text { aluga } 1 \text { caminhão }\end{array}$} \\
\hline Qual a área de abrangência? & \multicolumn{3}{|c|}{$\begin{array}{l}\text { Na região norte nos bairros: Morada da Serra, Morada do Ouro e } \\
\text { outros, a coleta é realizada nos supermercados como: Comper, dia-a- } \\
\text { dia e em alguns condomínios. }\end{array}$} \\
\hline Qual a frequência da coleta seletiva? & $\begin{array}{l}\text { Diariamente, exceto nos } \\
\text { supermercados e } 1 \mathrm{vez} \text { por semana } \\
\text { nos condomínios }\end{array}$ & $\begin{array}{l}\text { Utiliza-se balança } \\
\text { para pesagem? }\end{array}$ & Sim \\
\hline Que tipo de material é recolhido? & Tonelada/mês & \multicolumn{2}{|c|}{ Porcentagem $(\%)$ no total } \\
\hline
\end{tabular}




\begin{tabular}{|c|c|c|c|c|c|c|}
\hline \multirow{2}{*}{\multicolumn{2}{|c|}{$\begin{array}{l}\text { PET } \\
\text { PEAD }\end{array}$}} & \multirow{4}{*}{\multicolumn{3}{|c|}{$\begin{array}{l}\text { Não souberam responder - mas } \\
\text { permitiram que fizéssemos um } \\
\text { registro fotográfico do quadro de } \\
\text { anotações. }\end{array}$}} & \multirow{4}{*}{\multicolumn{2}{|c|}{ Não souberam responder }} \\
\hline & & & & & & \\
\hline \multicolumn{2}{|l|}{ Seda } & & & & & \\
\hline \multicolumn{2}{|l|}{ Papelão } & & & & & \\
\hline \multicolumn{7}{|c|}{4 - Comercialização } \\
\hline Material & \multicolumn{2}{|c|}{ Quem são os compradores? } & \multicolumn{3}{|c|}{ Com que frequência? } & Quanto é vendido? \\
\hline Papelão & \multicolumn{2}{|c|}{ Indústria } & \multicolumn{3}{|c|}{4 vezes nesse mês } & Não responderam \\
\hline Metais & \multicolumn{2}{|c|}{ Atravessador/sucateiros } & \multicolumn{3}{|c|}{ Não responderam } & Não responderam \\
\hline Vidro & \multicolumn{2}{|c|}{ Atravessador/sucateiros } & \multicolumn{3}{|c|}{ Não responderam } & Não responderam \\
\hline Plástico & \multicolumn{6}{|c|}{ É levado para unidade de beneficiamento, é comercializado com a indústria } \\
\hline \multicolumn{7}{|c|}{5 - Equipamentos e Veículos Utilizados } \\
\hline Equipamento & \multicolumn{2}{|l|}{\begin{tabular}{l|l} 
Quantidade \\
\end{tabular}} & \multicolumn{3}{|c|}{ Próprio } & Cedido \\
\hline Esteira & \multicolumn{2}{|c|}{1 - Não funciona } & \multicolumn{3}{|c|}{$\mathrm{X}$} & \\
\hline Prensa & \multicolumn{2}{|c|}{1} & \multicolumn{3}{|l|}{$\mathrm{X}$} & \\
\hline Elevador de carga & \multicolumn{2}{|l|}{1} & \multicolumn{3}{|l|}{$\mathrm{X}$} & \\
\hline Balança manual & \multicolumn{2}{|l|}{1} & \multicolumn{3}{|l|}{$\mathrm{X}$} & \\
\hline Carrinho de mão & \multicolumn{2}{|l|}{2} & \multirow{2}{*}{\multicolumn{3}{|c|}{$\mathrm{X}$}} & \\
\hline Caminhão coletor & 1 & & & & & Alugado \\
\hline \multicolumn{7}{|c|}{ 6-Saúde do trabalhador } \\
\hline \multicolumn{4}{|c|}{ A cooperativa oferece equipamentos de proteção individual (EPI's) } & \multicolumn{3}{|c|}{ Não } \\
\hline \multicolumn{4}{|c|}{ Quais os EPI'S são utilizados? } & \multicolumn{3}{|c|}{ Nenhum } \\
\hline \multirow{2}{*}{\multicolumn{4}{|c|}{ Quantos acidentes de trabalho foram registrados? }} & & te con & dro \\
\hline & & & & & $\begin{array}{l}\text { las já } \\
\text { eça. }\end{array}$ & m tempo, um corte na \\
\hline Que tipo de aciden & ocorreram? & & & & $\begin{array}{l}\text { a barr } \\
\text { vocanc }\end{array}$ & $\begin{array}{l}\text { e ferro caiu do elevador, } \\
\text { o corte na cabeça. }\end{array}$ \\
\hline
\end{tabular}

Organização: Ribeiro, 2019

Em relação as instalações e infraestrutura apresenta melhores condições comparadas a unidade I de beneficiamento, o galpão é cedido pela prefeitura, e conta com uma área de triagem e armazenamento, tem uma cozinha em funcionamento, dois banheiros, e um escritório que está desativado. Todavia, observou-se durante os trabalhos de campo, que o local está em condições precárias de funcionamento, a cozinha por exemplo não possui uma divisão.

A triagem da carga é feita diariamente, mediante a chegada no galpão. A figura 04 mostra o trabalho de triagem e separação do papelão e dos plásticos realizado pelas cooperadas, nota-se que os resíduos que chegam dos grandes geradores não são depositados seletivamente, pois são encontrados vários resíduos orgânicos misturadas. 
Figura 04. Separação dos materiais recicláveis da Coopermar II.

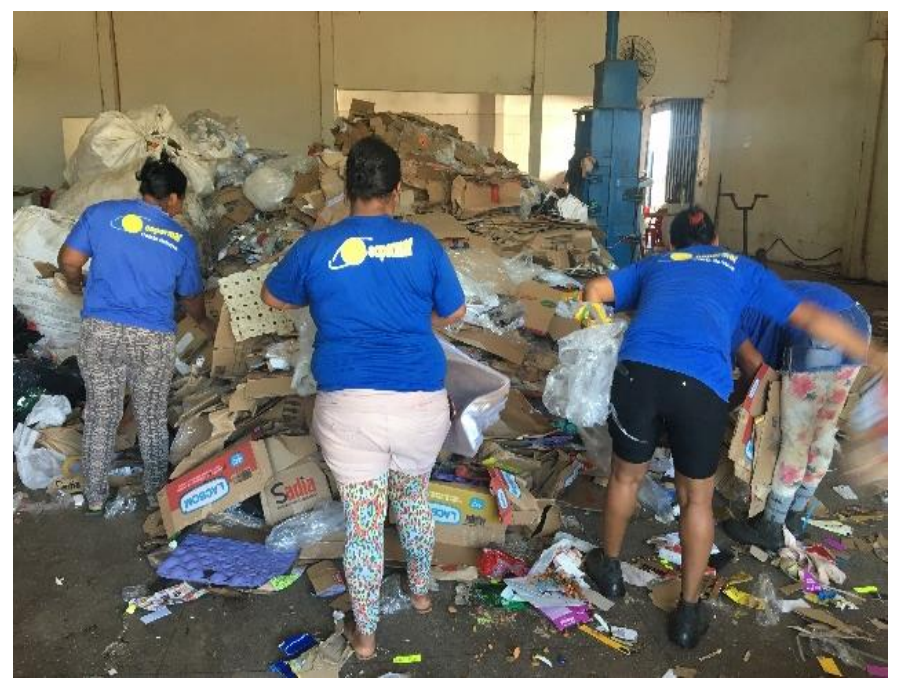

Fonte: RIBEIRO, 2018.

Sobre a coleta seletiva, as respostas nos questionários informam que a prefeitura retirou o caminhão da coleta, e que agora a cooperativa aluga um caminhão, o que prejudica ainda mais os rendimentos dos cooperados, pois precisam pagar o aluguel e o abastecimento.

Em relação a abrangência e atuação, as informações no quadro 4 mostra que a cooperativa coleta os resíduos na região norte do município principalmente nos supermercados e em alguns condomínios. Nos supermercados e redes atacadistas a coleta é realizada diariamente, exceto aos domingos, já nos condomínios é realizada uma vez na semana. Em relação aos materiais coletados, os que apresentam maior expressividade é o papelão e o plástico, sobre a quantidade coletada não souberam responder.

Os cooperados e cooperadas nos disseram, em conversas informais, que não há mercado para comercialização do vidro por falta de indústrias, e quando coletam esse tipo de material na maioria das vezes são potes, estes são vendidos para artesãs da região. Em relação ao alumínio, os cooperados comentam que este material é coletado nas ruas por catadores não cooperados e por isso não chegam à cooperativa.

Nas atividades diárias da cooperativa Coopermar Jardim Umuarama todos os materiais coletados passam pelos processos de triagem e compactação, posteriormente são registrados e inseridos em tabelas manuscritas em um mural fixado na parede, assim, todos tem acesso às informações referentes a produção realizada no mês já que todo o trabalho e a renda são divididos igualmente.

Após o processo de separação dos materiais coletados, os cooperados organizam nos subgrupos que são chamados de: plástico duro, que são as embalagens de produtos de limpeza, 
as caixas de hortifrúti (PP e PEAD); as caixas de leite longa vida, garrafas de refrigerante, garrafas de água mineral, óleo de cozinha (PET, PEAD e PP) o plástico fino; as sacolas em geral (PEBD).

Em relação aos equipamentos que a cooperativa disponibiliza, segundo os dados do questionário são: 1 esteira que não está funcionando, 1 prensa, 1 elevador de carga, 2 carrinhos de mão.

Em relatos, os cooperados nos disseram que não ter a esteira funcionando dificulta o trabalho que tem que ser manual, diminuindo a produção no dia e acumulando trabalho e precarizando ainda mais as condições de trabalho na cooperativa.

Observou-se durante os trabalhos de campo na cooperativa, que os cooperados não utilizam EPI's, separam todos os tipos de resíduos, que chegam em grande parte misturados com resíduos não recicláveis sem utilizar luvas e utilizam a prensa sem nenhum tipo de equipamento de segurança, colocando em risco suas vidas.

Quando perguntamos no questionário se a cooperativa oferecia os equipamentos, as respostas conforme o quadro 4 apontam para cinco respostas de que não possuem esses EPI's, e somente um respondeu que sim, porém, o que ficou perceptível nos trabalhos de campo, é que os cooperados não os utilizam.

Dentre o maquinário necessário para o funcionamento de uma cooperativa de materiais recicláveis, temos a prensa como elemento importante, pois "economiza espaço na armazenagem e otimiza o transporte das cargas comercializadas, aumentando o seu valor." (LAJOLO, 2003, p. 71). Desse modo, o equipamento auxilia na melhoria das condições de trabalho, à medida que, facilita a acomodação dos fardos, deixando o galpão organizado e liberando espaço para outros processos, como exemplo, a triagem. Ainda, aumenta o valor dos resíduos a serem comercializados em relação ao não enfardados.

As prensas são utilizadas para produzir os fardos dos plásticos tipos (PP, PEAD, PEBD - e PET - Poli Tereftalato de Etileno) conforme as figuras 05 e 06. 
Fotos 05 e 06: Fardos de Pead e Pebd prensados
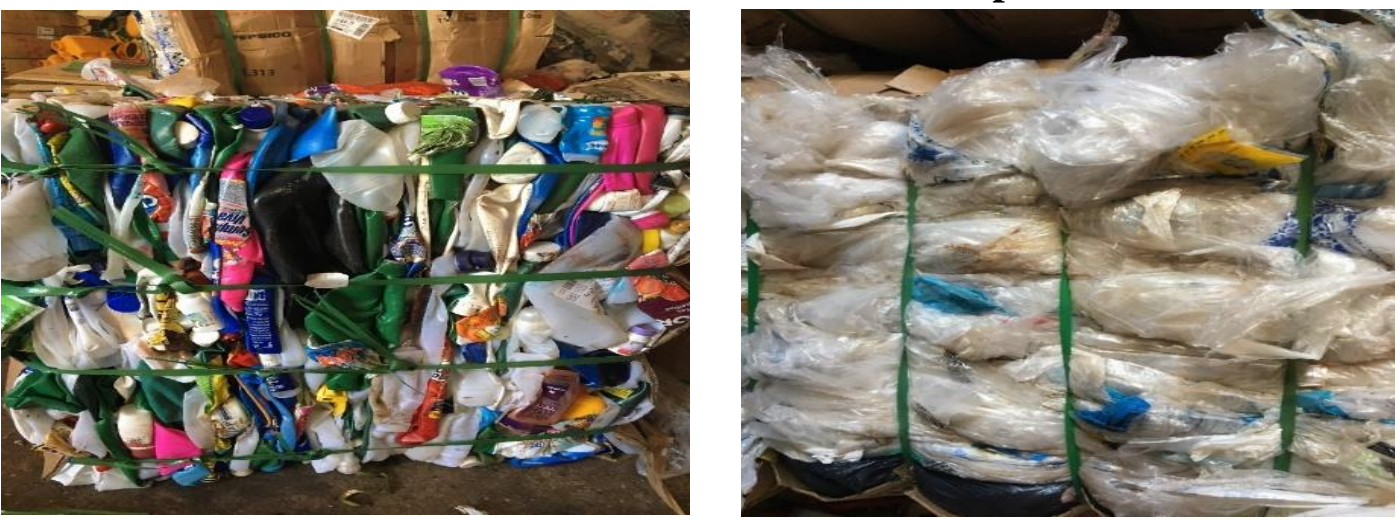

Fonte: Ribeiro, 2018.

Embora a prensa apresenta contribuições para a cooperativa, é a única em funcionamento, assim, constatou-se que há falta de investimento pelo poder público em infraestrutura e equipamentos que possam auxiliar na melhoria das condições de trabalho.

Em relação a comercialização dos materiais, os dados apontam que o papelão é o único comercializado direto com a indústria, os demais, por exemplo, os metais, são comercializados por meio de atravessadores, os potes de vidro são comercializados com artesãs locais, e o plástico é levado para a Cooperativa Coopermar unidade de beneficiamento.

Dentre as observações e dados coletados, percebe-se que a cooperativa Coopermar necessita de reorganização estrutural e organizacional, mesmo oferecendo melhorias nas condições de trabalho, quando comparados aos trabalhadores informais no lixão, a cooperativa de catadores de materiais recicláveis necessita de investimentos e parceiras, pois apresenta pouco ou nenhuma participação efetiva na gestão e no gerenciamento dos resíduos sólidos para o município de Cuiabá.

\section{CONSIDERAÇÕES FINAIS}

Sabe-se que um dos maiores desafios das cooperativas de materiais recicláveis é oferecer melhores condições de trabalho e a geração de uma renda digna para os trabalhadores, sendo uma saída da situação antes vivenciadas por estes no lixão. A formação das cooperativas possibilita novas relações entre os grupos de catadores de materiais recicláveis, criando diversas melhorias nas condições de vida e cidadania.

As cooperativas quando são organizadas de maneira correta, ou seja, tendo infraestrutura, maquinário e parcerias para realizarem o trabalho de maneira digna, melhora as condições de trabalho e de vida dos catadores e catadoras de materiais recicláveis, sendo uma 
alternativa para sair da situação de exploração vivenciadas por estes no lixão, ou em outros trabalhos informais.

Conforme aponta a PNRS (2010) a contratação das cooperativas pela prefeitura municipal como prestadora de serviços, contribui para a valorização da categoria, e para a expansão de um sistema de coleta seletiva, melhoraria a infraestrutura, a qualidade de trabalho e de materiais coletados, consequentemente, melhoria nas vendas de modo a acontecer de forma direta com as indústrias.

Os questionários e os trabalhos de campo realizados nas cooperativas Coopermar Unidade de Beneficiamento I e II, nos permitiu compreender parte da organização do trabalho destes catadores e catadoras de materiais recicláveis. As relações que se estabelecem a partir das vivências, do trabalho e das delimitações do território, que são efetivadas à medida que se apropriam do espaço, e criam múltiplas relações sociais e econômicas, como por exemplo, os resíduos plásticos que são comercializados entre as duas cooperativas são exemplos que provam que há possibilidades de trocas entre as cooperativas e criação de redes de comercialização.

Considera-se que as duas unidades da cooperativa Coopermar encontram-se em condições precárias, sem condições de ampliar o número de cooperados, o que reflete a necessidade de valorização do trabalho destes cooperados e cooperadas, e incentivo do poder público municipal.

O trabalho desenvolvido sem subsídios, sem infraestrutura corrobora para que esses catadores continuam trabalhando em condições extremas, ou seja, há uma urgência no cumprimento das propostas e metas da PNRS (2010), para que assim, esse grupo de catadores de materiais recicláveis possam ter seus direitos garantidos e possam participar de modo integral da gestão e gerenciamento dos resíduos sólidos.

Nesse sentindo, conforme as orientações da PNRS (2010), considera-se a necessidade da implementação da coleta seletiva que contemple as necessidades do município, infraestrutura adequada das cooperativas para o desenvolvimento do trabalho, como sede própria, galpão espaçoso, banheiros, e equipamentos adequados, caminhões, dentre outros, além de sua contratação.

Além disso, acredita - se que as ações educativas quando promovidas em parcerias com as cooperativas, contribui de forma significativa para o processo educativo da população que conhecedora da rota de seus resíduos e da importância do descarte seletivo e coleta seletiva contribui como agente ativo no processo. 


\section{REFERÊNCIAS}

ALVES. G. O Novo (e precário) mundo do trabalho. Reestruturação Produtiva e crise do sindicalismo. São Paulo. Boitempo, 2000.

ABRELPE. Associação Brasileira de Empresas de Limpeza Pública e Resíduos Especiais. Disponível em https://abrelpe.org.br/ . Acesso em 04/11/2020.

BAUMAN, Z. Vida para consumo: a transformação das pessoas em mercadoria. Tradução Carlos Alberto Medeiros. Rio de Janeiro: Jorge Zahar Ed., 2008.

BRASIL. PLANO NACIONA DE RESíDUOS SÓLIDOS. Ministério do Meio Ambiente, Instituto de Pesquisa Econômica Aplicada (IPEA), 2012.

BRASIL. POLÍTICA NACIONAL DE RESÍDUOS SÓLIDOS. Lei nº12.305/2010.

CEMPRE. Compromisso Empresarial para Reciclagem. Disponível em:

http://www.cempre.org.br/. Acesso em 04/011/2020.

CANTÓIA, S. F. Coleta Seletiva Municipal, Educação Ambiental e organização de catadores de materiais recicláveis na vertente paulista da bacia do rio Paranapanema. Presidente Prudente: [s.n], 2012325 f: il. Tese de Doutorado em Geografia. Faculdade de Ciência e Tecnologia - Universidade Estadual Paulista - UNESP, 2012.

Lajolo, R. D. (coord.) Cooperativa de Catadores de Materiais Recicláveis -Guia para implantação (2003). São Paulo: Instituto de Pesquisas Tecnológicas -Sebrae.

LAUREANO, A. T. Estudos geofísicos no aterro sanitário de Cuiabá, MT. - 2007. 149 f. Dissertação de Mestrado. Instituto de Ciências Exatas e da Terra. UFMT - Universidade Federal de Mato Grosso - MT. 2007.

LOGAREZZI. A. Contribuições para o gerenciamento de resíduos sólidos e ações de Educação Ambiental. In: LEAL, A. C. Resíduos sólidos no pontal do Paranapanema. Presidente Prudente: UNESP/FCT, 2004.

Educação Ambiental em resíduo: uma proposta de terminologia. In: CINQUETE, H.C.S., LOGAREZZI, A. (Org.) Consumo e Resíduos - Fundamentos para o Trabalho Educativo. São Carlos: EdUFSCar, 2006.

RAFFESTIN, Claude. Por uma geografia do poder. Tradução de Maria CecíliaFrança. São Paulo: Ática, 1993.

SANTOS, J. G. A logística reversa como ferramenta para a sustentabilidade: um estudo sobre a importância das cooperativas de reciclagem na gestão dos resíduos sólidos urbanos. REUNA, Belo Horizonte - MG, Brasil, v.17, n.2, p. 81-96, abr. - jun. 2012.

SINGER, P. SOUZA, A. R. de (Orgs) A economia solidária no Brasil - A autogestão como resposta ao desemprego. São Paulo. Contexto, 2003.

SNIS. Diagnóstico anual de resíduos sólidos. Disponível em http://www.snis.gov.br/diagnosticos/residuos-solidos. Acesso em

XIBERRAS. M. As teorias da Exclusão. Para uma construção do Imaginário do desvio. Instituto Piaget- Epistemologia e Sociedade. Lisboa, 1993. 
ZANIN. M. GUTIERREZ. R.F. (Orgs.). Cooperativas de Catadores: Reflexões sobre a prática. São Carlos, Claraluz, 2011.

Recebido em 06 de novembro de 2020

Aceito em 02 de maio de 2021

Publicado em 07 de maio de 2021 